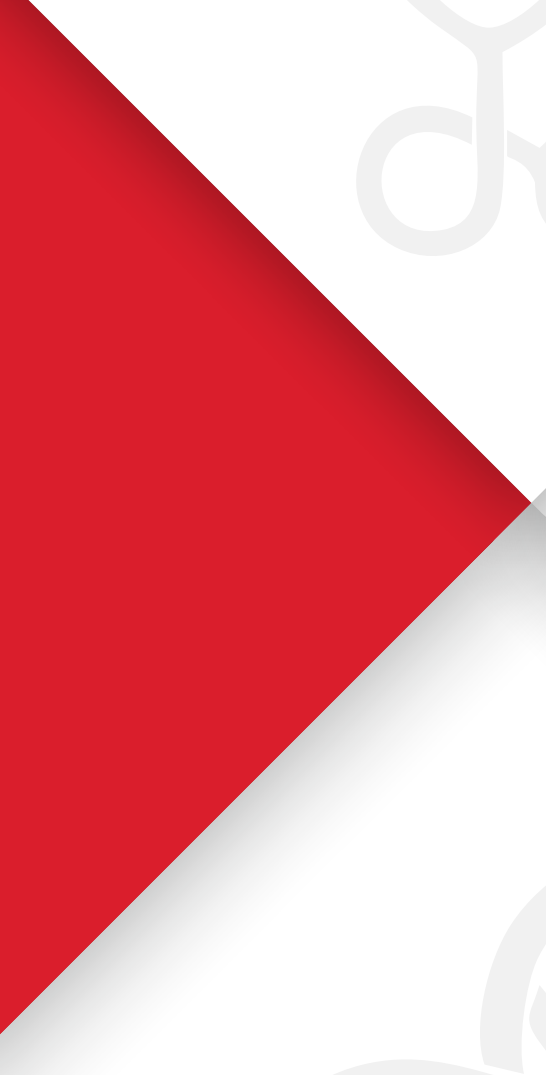

Volume 3 • Issue 2 - May-August 2020
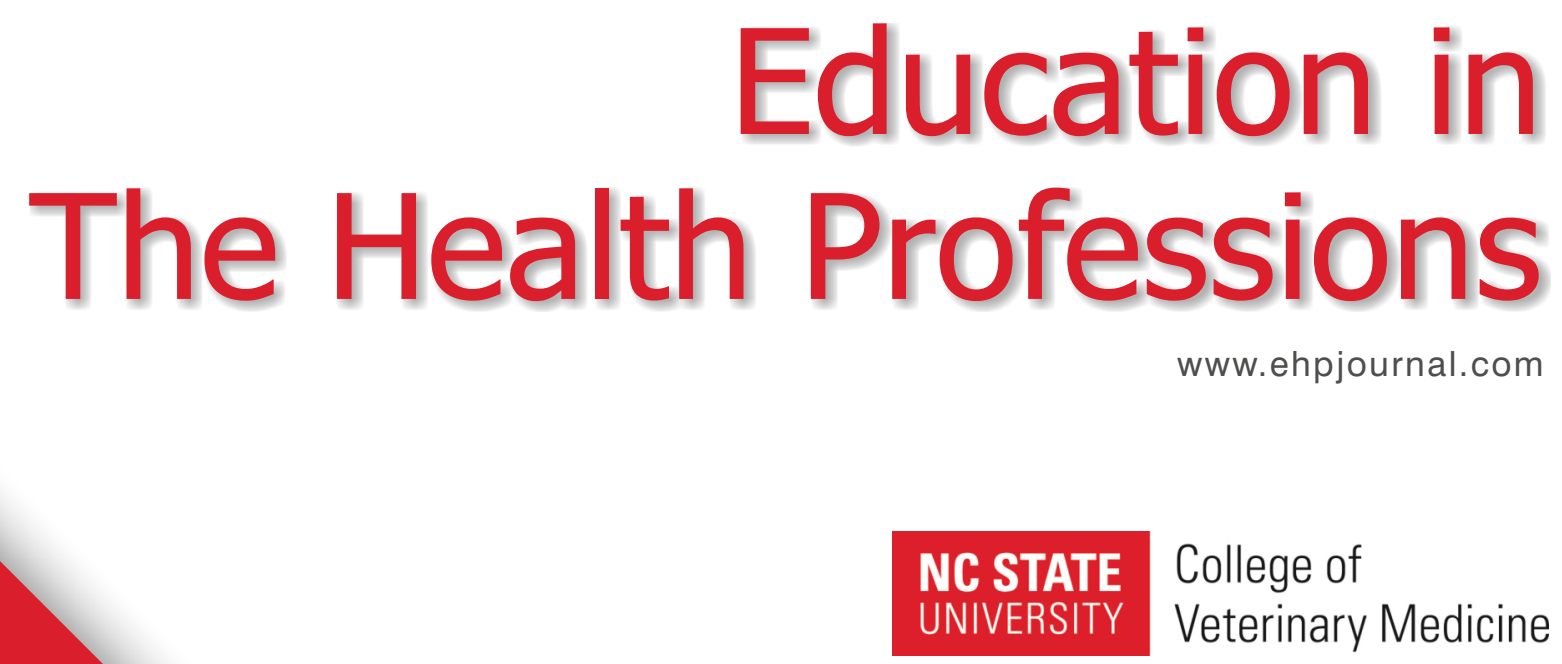

North Carolina State University College of Veterinary Medicine (USA) 


\title{
Serious Gaming as an Active Method of Learning Applied Antibiotherapy in Swine Veterinary Medicine
}

\author{
Perle Emilie Zhitnitskiy \\ Department of Population Veterinary Medicine, College of Veterinary Medicine, University of Minnesota, Saint Paul, MN, USA
}

\section{Abstract}

Background: Serious games have been increasing in popularity within health sciences education. Games can improve learning by increasing students' engagement and by developing their analytical, critical thinking, and teamwork skills. Objective: The objective of this study was to evaluate the efficacy of a board game to teach applied swine antibiotherapy to veterinary students in their clinical year. Methods: Students were quizzed pre- and postclass to evaluate their knowledge retention. An anonymous seven-question survey was given to the students at the end of class to assess their satisfaction with the board game. Results: Students' quiz scores increased by 1.34 points on average between the beginning and end of class $(P=0.03)$. Students unanimously enjoyed playing the board game and recommended that it continued to be used in the next iteration of the course. Discussion: Using serious gaming proved to be an enjoyable method of reviewing antibiotherapy and applying it to swine clinical cases in this population of veterinary students. Implementing serious gaming in health sciences education requires a time investment for preparation but provides a richer experience for students and faculty alike.

Keywords: Active learning, serious gaming, swine medicine, veterinary education

\section{INTRODUCTION}

Gamification and serious gaming might have been used interchangeably in the literature; however, their definitions are slightly different. Gamification refers to "the application of the characteristics and benefits of games to real-world processes or problems." ${ }^{[1]}$ With gamification, partial game structure is used to increase motivation or improve users' experience. Points, badges, leaderboards, and avatars are among the most common game elements to be implemented. Examples are numerous in modern, day-to-day life from coffee reward programs to language learning applications on smartphones. Gamification needs to be differentiated from serious gaming which encompasses games designed with the intent to provide users with education. Serious gaming was originally described as video games "for which the original intention is to combine with consistency, both serious aspects such as [...] teaching, learning, communication, or the information, with playful springs from the video game." ${ }^{\text {[2] }}$ The definition has since then been extended to other types of games such as board and card games..$^{[1]}$ Serious games are both standalone learning objects and fully developed games with their own setup, gameplay, and conditions for victory.

\begin{tabular}{|l|l|}
\hline \multicolumn{2}{|c|}{ Access this article online } \\
\hline Quick Response Code: & Website: \\
\hline & www.ehpjournal.com \\
\cline { 2 - 2 } & \\
\hline
\end{tabular}

The number and diversity of serious games used in health professional education have been increasing. ${ }^{[3]}$ Serious games have been shown to increase students' engagement with course material ${ }^{[4,5]}$ and can be at least as effective as other teaching methods. ${ }^{[1]}$ Playing can be categorized as part of experiential learning and has been described as an analytic learning process. ${ }^{[6]}$ Games can engage students in Kolb's learning cycle that includes four steps: doing (the experience itself), reflecting about the experience, conceptualization (learning from the experience), and planning or active experimenting (based on what one has just learned) [Figure 1].

Serious gaming can develop students' analytical skills and strategic thinking ${ }^{[7]}$ as well as promote collaborative learning if the game is multiplayer or if students play in teams. ${ }^{[8]}$

Address for correspondence: Dr. Perle Emilie Zhitnitskiy, College of Veterinary Medicine, University of Minnesota, AS/VM 385J, 1988 Fitch Ave, Saint Paul, MN 55108, USA. E-mail: pboyer@umn.edu

This is an open access journal, and articles are distributed under the terms of the Creative Commons Attribution-NonCommercial-ShareAlike 4.0 License, which allows others to remix, tweak, and build upon the work non-commercially, as long as appropriate credit is given and the new creations are licensed under the identical terms.

For reprints contact: reprints@medknow.com

How to cite this article: Zhitnitskiy PE. Serious gaming as an active method of learning applied antibiotherapy in swine veterinary medicine. Educ Health Prof 2020;3:63-9.

Submission: 27.02 .2020 Acceptance: 27.04 .2020 Web Publication: 27.07.2020 


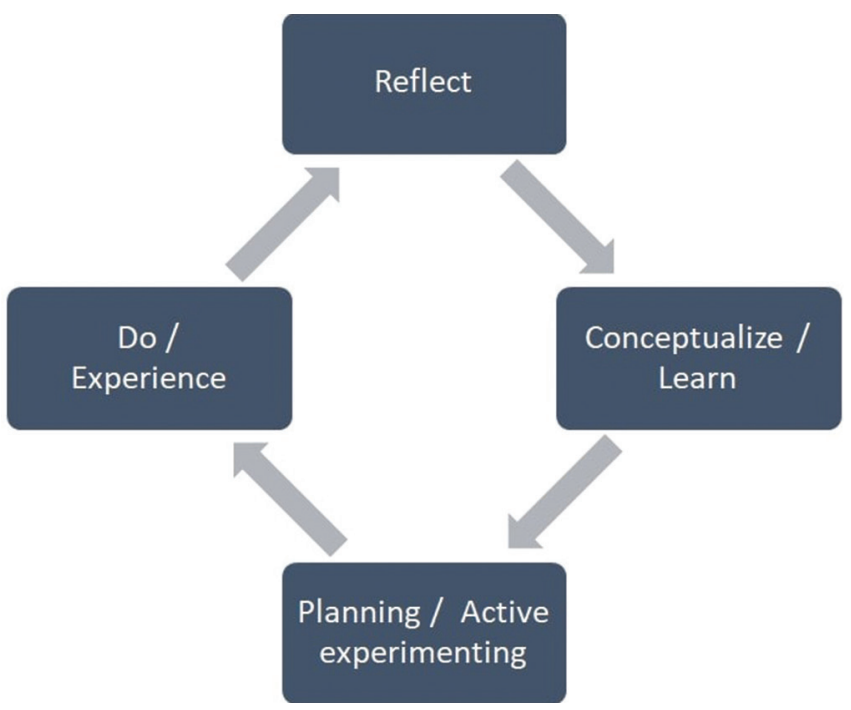

Figure 1: Kolb's experiential learning cycle

Obstacles to serious gaming include the high cost of the digital options and instances when the game itself becomes "more memorable than the message"[9] and is a distraction to the learning process for students. Serious games do not have to be digital; low-cost options such as card games and board games have been developed for both medical and veterinary education to teach a variety of topics from disease outbreak investigation to radiographic image quality. ${ }^{[5,10-14]}$

To the best of our knowledge, this is the first complete description of an active class session using a specifically designed board game to teach applied antibiotherapy to veterinary students.

\section{Methods}

This study was conducted in accordance with the institutional review board of the university under protocol number 00008573.

\section{Description of the course}

Introduction to swine health and production (CVM 6854) is an optional clinical rotation offered to $4^{\text {th }}$-year veterinary students who want to learn more about the role of veterinarians in the swine industry. This 2-week course is offered once a year. Typical enrollment is between 10 and 15 students, and 13 students were enrolled at the time of the study. Topics covered in the class are varied and include judicious use of antibiotics in swine medicine. This antibiotherapy content was historically delivered in a 2-h lecture summarizing the most common commercial products licensed to treat swine, their chemical compound, their indications, and how to treat the animals without compromising food safety or public health. Most of this content is presented in a previous $2^{\text {nd }}$-year course of clinical pharmacology, making this a review and application session. As such, the instructor was able to change the delivery method for an active learning session using a self-designed e-book and board game.

\section{Creation of the e-book and its associated worksheet}

An e-book was developed as a fast resource for students to refer to when they needed information regarding the major antimicrobial classes. Eleven chapters covered the major antibiotic classes including information on pharmacokinetics and pharmacodynamics as well as two knowledge checks for readers to self-evaluate their understanding of the chapters. The e-book was created in collaboration with the University of Minnesota Libraries on their platform, Pressbooks (Pressbooks, Montreal, Canada).

A worksheet was distributed to the students with ten open-ended questions focusing on the antimicrobial mechanism of action, the best route of administration, or which antimicrobials were prohibited in food-animal species, so that the students would read and explore the different parts of the e-book.

\section{Design of the board game}

The game design is inspired by the classic American game, Chutes and Ladders, itself originating from the ancient Indian game Moksha Patam. The original games are based solely on chance and rely on the players rolling a dice to move their token forward on a track drawn on the board. If a player's token lands on a ladder, it gets to take a shortcut and moves faster toward the endpoint, whereas landing on a chute takes the player backward and closer to the starting point. The player who reaches the finish point the fastest is declared the winner of the game.

The original board game was modified and adapted to teach antibiotherapy to veterinary students while keeping its competitive aspect. Based on Bochennek et al., this game fits in the category of dice and luck games with a two-stage learning cycle (experience and reflection/review). ${ }^{[10]}$

\section{Board}

The board game was designed a serpentine route and consisting of 105 squares, including a start and finish squares. Ladders in the shape of a pig's tail and chutes looking like pig snouts were added to link the squares from various parts of the board. Squares that were neither a starting nor an endpoint of a chute or ladder were separated into three categories: a green square with a question mark, an orange square with a warning sign, and a pink square with a veterinary caduceus [Figure 2]. Six tokens and a six-faced dice were added to the set.

\section{Cards}

Three sets of cards were created to match the color-coded squares. The green cards had a question mark on one side and a multiple-choice or short-answer question on the other. The key to the question was given at the bottom of the card upside down [Figure 3a]. The questions were designed to check the basic knowledge of antibiotics of the students playing. Some of these questions originated from the quizzes given to students in their $2^{\text {nd }}$ year of the DVM program, while others were published in the literature. ${ }^{[13]}$ Pink cards had a veterinary caduceus on one side and a short clinical case on the other [Figure 3b]. These cases described a real-life 
scenario of an individual pig or of a herd suffering from a particular ailment. A short history of the case, as well as clinical signs, was added to help students narrow down the list of probable causes and therefore select the appropriate antibiotic. Cases were created by the instructor based on common swine disorders encountered in practice.

Finally, the orange cards were designed as disturbers to add another layer of challenge to the game. One side had a warning sign and the other had a short statement that asked the player to do something that could either help move up the board or put them back [Figure 3c].

The detailed gameplay is presented in Appendix A.

\section{Organization of the class session}

The class session was comprised two 50-min time slots. After explaining to the students the learning objectives for this session, the instructor shared the schedule and distributed the first quiz (pre). Students took approximately $5 \mathrm{~min}$ to complete this quiz. After that, the worksheets were distributed and students were given $20 \mathrm{~min}$ to read through the e-book and answer the questions. At the end of this time period, the instructor reviewed the worksheet with the students, sharing the answers, clearing misunderstandings, and answering questions. At this point in time, the $1^{\text {st }} \mathrm{h}$ was

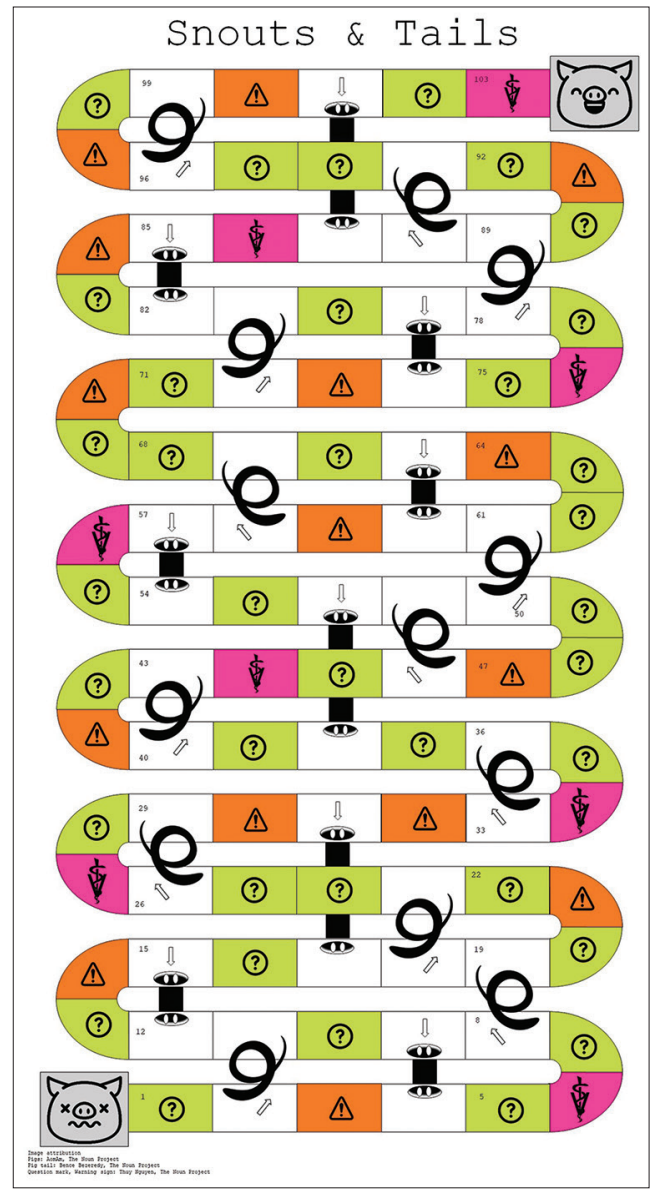

Figure 2: Snouts and Tails board game over and the board game was installed. Although Chutes and Ladders is typically played as individuals, students played the antibiotherapy board game in five teams of two and one team of three. This activity lasted for 40 min until the students were given their second quiz (post). Questions were identical between the two quizzes to identify progress as well as information that was still misunderstood. The instructor provided the students with the correct answers to the quiz and distributed the anonymous surveys regarding the board game. Students left the completed surveys on the table before leaving the classroom.

Evaluation of the game and of the session effectiveness Statistical analysis of the difference in students' performance on the pre- and postclass quizzes was done with a Chi-square test using the SAS software version 9.4 (SAS Inc., Cary, USA).

In addition, students were given a seven-question survey regarding the board game [Table 1]. The survey was anonymous and given to the students after ensuring them that their answers would not affect their grade or their progression through the curriculum. Descriptive statistics of the students' answers to the survey were conducted.

\section{ResULTS}

\section{Pre- and postlearning experience test results}

The students' average score was 5.41 out of 10 (std 1.98) before the class session and 6.75 out of 10 (std 1.29) at the end of the class. This represents an increase of 1.34 points on average on a ten-question quiz, and this difference was statistically significant $(P=0.03)$. Students did better at the end of the class session for questions $1,2,3,6,7,8$, and 9; the number of right answers was constant for questions 4 and 10 while they decreased for question 5 [Figure 4].

\section{Students' evaluation of the board game}

Overall, the students had a positive opinion of the antibiotherapy board game. All students either agreed or totally agreed that they enjoyed playing the game, found it interesting, and helped them learn more about antimicrobials [Figure 5]. One student neither agreed nor

\section{Table 1: Questions of the survey regarding the} antimicrobial game

\begin{tabular}{ll}
\hline Type & Question \\
\hline 5-point Likert & I enjoyed playing the antimicrobial game \\
scale (totally & The game's rules were easy to understand \\
agree-totally & I found the antimicrobial game interesting \\
disagree) & The game helped me reinforce my \\
& knowledge of antimicrobials \\
& I think this game should continue to be \\
& used in the class next year \\
& What worked well with this game? \\
& List one thing that could have made the \\
Open ended & experience better
\end{tabular}




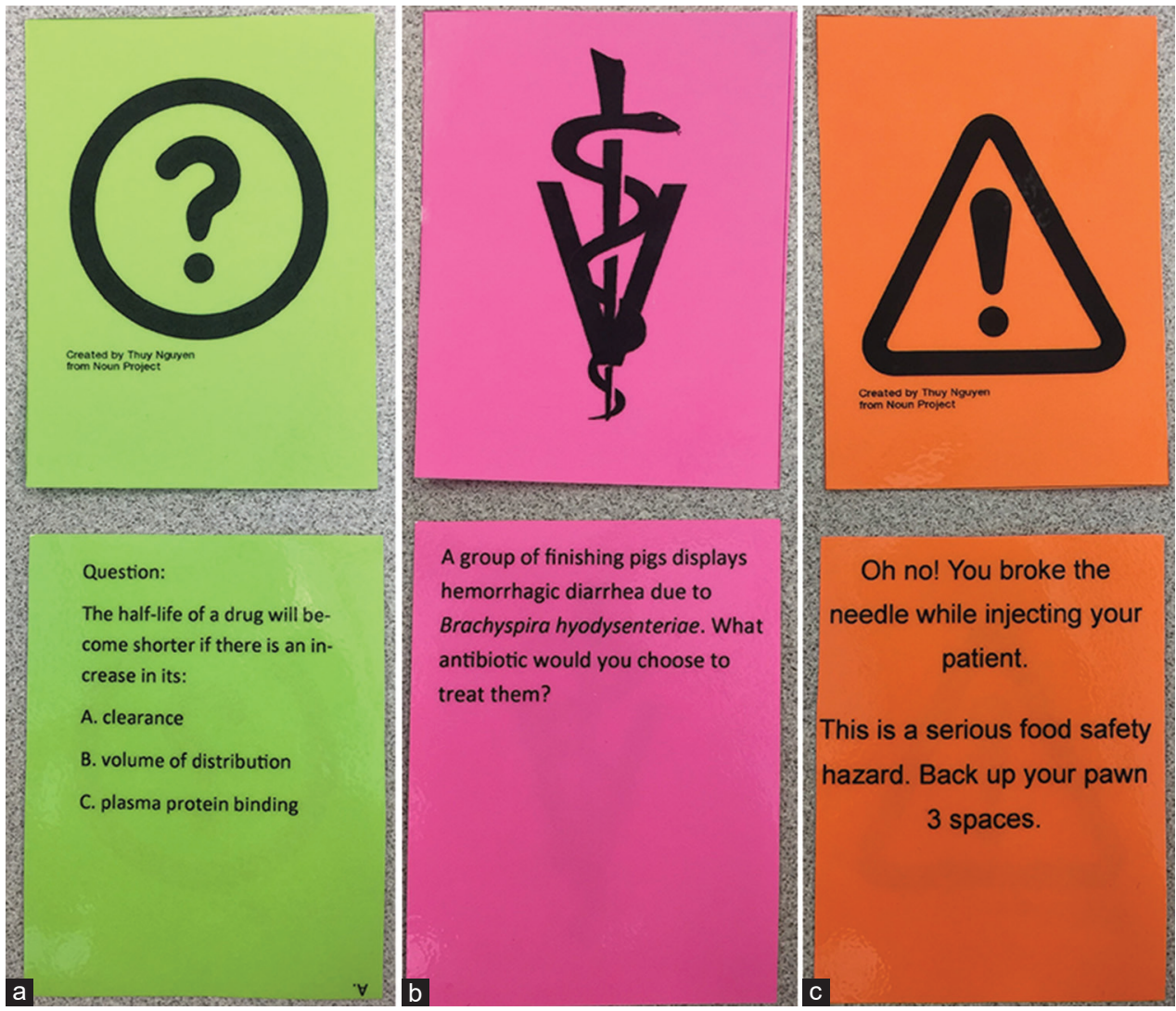

Figure 3: (a-c) Representative card examples from the Snouts and Tails game (back and front)

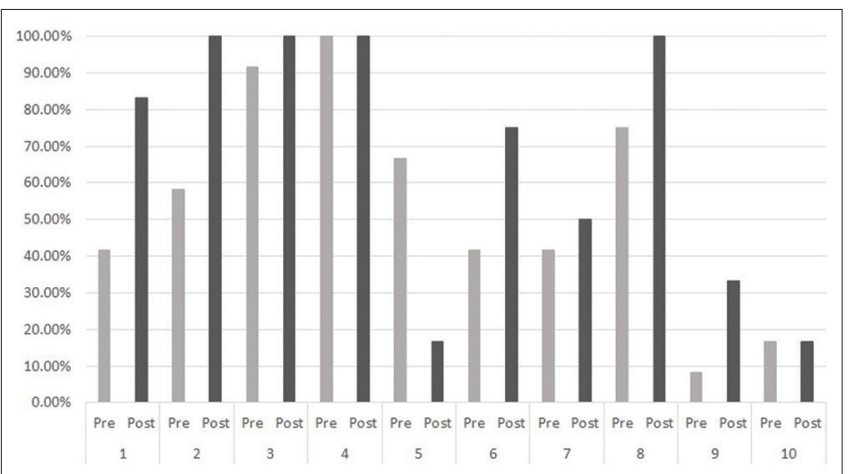

Figure 4: Percentage of right answers pre- and postclass session for each question

disagreed regarding the simplicity of the rules. This was corroborated by some of the answers to the open-ended questions in which students requested more guidance on the proper use of the "orange cards." Other than clearer rules, two students mentioned that the size of the board was too small for a group of 13 , and three students thought that the board needed more pink squares that required them to apply their antibiotic knowledge to a clinical situation.

Examples of positive feedback included students explaining they enjoyed playing in pairs instead of by themselves because group discussions and working in teams was helpful to make decisions.

\section{Discussion}

The use of an antibiotherapy game improved students' ability to apply theoretical knowledge to clinical cases in swine medicine in this cohort confirming the previously published findings that educational games can be an efficient way to teach students in health sciences. ${ }^{[1]}$

A wide variety of cards and board games are being incorporated into health professions education, ${ }^{[3,5,10-12]}$ and Snakes and Ladders has been used previously for medical students. ${ }^{[4]}$ Having fun favors students' learning in part because it increases students' motivation to play the game multiple times and learning all the while. ${ }^{[10]}$ Indeed, studies have shown that repetition increases the effectiveness of games as a learning strategy. ${ }^{[15,16]}$ The antibiotherapy game presented in this study was well-received by the students who unanimously recommended that it continued to be used in the future iterations of the course. Since the end of the course, students have stopped by the instructor's office to borrow the game and play it on their own, testifying of their enjoyment and/or interest in the topic.

Best practices recommend using serious games in association with other methods of learning as it increases students' retention of the content. ${ }^{[15,16]}$ In this example, students had to work through a worksheet in conjunction with an instructor-designed e-book to remember and retrieve previously studied information on antimicrobial classes, spectrum, and mode of 


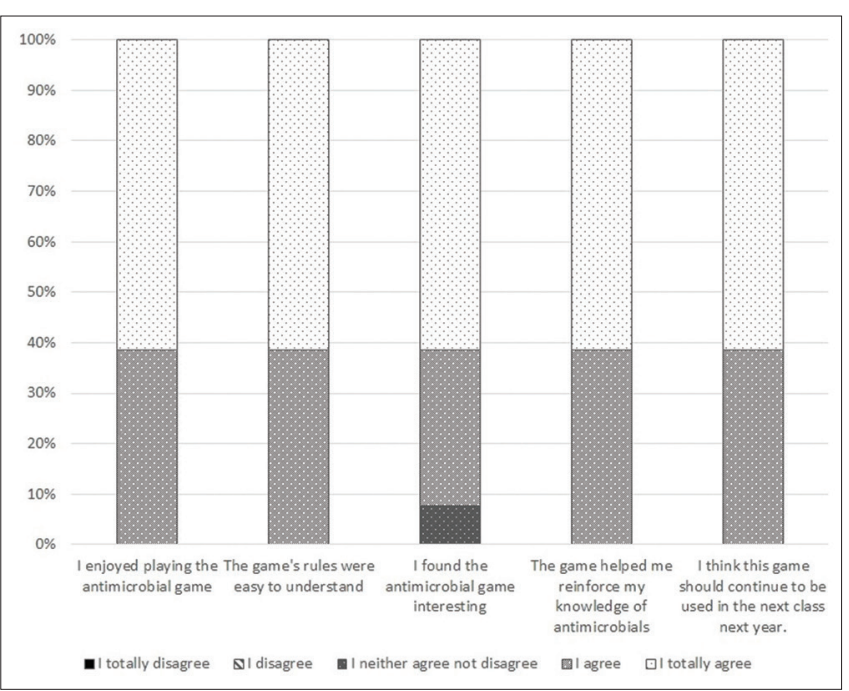

Figure 5: Students' answers to the survey regarding the antimicrobial game

action. Overall, the session was successful because students' quiz scores improved by $13 \%$ after the class compared to before the class.

The students appreciated the variety of activities and the fun element brought forward by the antibiotherapy game. The relative impact of each of the activities included in the session on the final test score remains unclear however. Quizzing the students twice in addition to reading the e-book and playing the game might have had an influence on this result. Indeed, in their book Make It Stick, Brown et al. underline the powerful tool that is retrieval, also called testing effect, by quoting Aristotle: "exercise in repeatedly recalling a thing strengthens the memory."[17] The impact of repeated testing has been proved to improve long-term retention in medical residents ${ }^{[18]}$ and has been shown to be more efficient than self-explanation as a learning method. ${ }^{[19]}$ It is especially impactful when the retrieval session are spaced in time, and students are provided with feedback to improve upon their performances. ${ }^{[20]}$ Therefore, the impact of the pre- and postclass quizzes needs to be considered in the improvement of knowledge scores.

Interestingly, several students mentioned an "appropriate" level of questions and cases included in the board game so that they felt challenged but not discouraged. The importance of the level of difficulty encountered in an educational game has been previously reported in a study with medical students and residents. ${ }^{[21]}$ The author concluded that the presented game was too complex for the medical students who, although enjoyed the experience, did not benefit from it as much as the residents. This concept has been further developed by studying players' electroencephalograms and physiological features such as heart rate and blood pressure as well as conducting questionnaires assessing players' emotional state. ${ }^{[22]}$ The results were that depending on the level of difficulty of the game, players were experiencing dramatically different emotional states. "The easy difficulty was related to a state of low pleasure, low pressure, low arousal, and low motivation which was determined as boredom. The medium difficulty elicited higher arousal than the easy difficulty, as well as higher pleasure, higher motivation, and higher amusement. It was thus defined as engagement. Finally, the hard condition was associated to anxiety since it elicited high arousal, high pressure, and low pleasure." Therefore, instructors are encouraged to create games that have an appropriate level of difficulty for their learners or that could adapt as their learners progress.

In this study, the proportion of students who answered question 10 correctly remained constant, whereas it declined for question 5. Question 5 asked the students if two antimicrobials could be used in synergy, considering that they were bacteriostatic. The correct answer was false because even though they are both bacteriostatic, the two components target a similar location in the bacteria and might push each other out of the binding site. Students might have remembered from the session that the two antimicrobials listed were indeed bacteriostatic and chose to answer "true" based on that information. Question 10 focused on in-depth knowledge of a swine-specific antibiotic and asked students to find the incorrect statement in a list. Best practices in multiple-choice question writing discourage instructors from using negation in their question stem. ${ }^{[23-25]} \mathrm{A}$ review of the use of a multiple-choice question in medical education shows that question construction is essential in providing a fair evaluation of students' knowledge. ${ }^{[26]}$ Indeed, any confusion over grammatical structure makes the test less reliable because students' answers do not reflect their mastery of the topic.

Prensky has reported that games can facilitate learning through collaboration and peer-learning. ${ }^{[8]}$ Although Chutes and Ladders was not designed initially as a collaborative game, students were asked to play in teams of two or three during the class session. Several mentioned in the survey that being able to discuss with a classmate before giving their answers was helpful and participated in "being in a friendly, judgment-free environment." Previous work has shown that veterinary students can engage in valuable collaborative learning ${ }^{[27,28]}$ even though their default attitude tends to be skeptical regarding what they can learn from their peers. Failures in effective peer learning often hinge on students' lack of preparation before the collaborative activity and their perception that meaningful collaborative processing of the information is not necessary to accomplish the objective of the activity. ${ }^{[28,29]}$ Educators need to be mindful of these parameters and promote accountability as well as share clear expectations of each participant's responsibilities.

\section{ConcLusion}

Serious gaming associated with the use of an instructor-designed e-book, pre/post-quizzing, and worksheet review proved to be an effective method to review antibiotherapy with veterinary students in their clinical year. Student application ability improved and all students enjoyed playing the game. Serious games are time-consuming to 
design and can seem challenging to implement. However, they are a low stress means to increase testing and retrieval into a class session and facilitate students' learning. Collaborative gaming can be of added value as it encourages peer-learning opportunities.

\section{Acknowledgments}

The author would like to thank Kristi Jensen and Jennifer Englund for their invaluable help in the design of the e-book and board games as well as Dr. Erin Malone and Mr. André Nault for their help with the review of this paper.

\section{Financial support and sponsorship}

Financial support for this study was provided from the Teaching Sprint Program from the Center for Educational Innovation at the University of Minnesota.

\section{Conflicts of interest}

There are no conflicts of interest.

\section{References}

1. Gentry SV, Gauthier A, L'Estrade Ehrstrom B, Wortley D, Lilienthal A, Tudor Car L, et al. Serious gaming and gamification education in health professions: Systematic review. Med Internet Res 2019;21:e12994. Available from: http://www.ncbi.nlm.nih.gov/pubmed/30920375. [Last accessed on 2020 Jan 17].

2. Alvarez J, Damien D. An introduction to Serious game Definitions and concepts. In: Fauquet-Alekhine P, Soler L, editors. Serious Games \& Simulation for Risks Management. Larsen Science; 2011. p. 10-5. Available from: http://www.ludoscience.com/EN/diff usion/628-An-introduction-to-Serious-game---Definitions-and-co ncepts.html. [Last accessed on 2020 Jan 29].

3. Wang R, DeMaria S, Goldberg A, Katz D. Systematic review of serious games in training health care professionals. Simul Healthc J Soc Simul Healthc 2016;11:41-51. Available from: https://insights. ovid.com/crossref?an=01266021-201602000-00006. [Last accessed on 2020 Jan 22].

4. Golchai B, Nazari N, Hassani F, Nasiri E, Nejad RG, Jafari Z. Snakes and ladders: A new method for increasing of medical students excitement. Procedia Soc Behav Sci 2012;47:2089-92.

5. Buur JL, Schmidt PL, Barr MC. Using Educational games to engage students in veterinary basic sciences. J Vet Med Educ 2013;40:278-81. Available from: https://jvme.utpjournals.press/d oi/10.3138/jvme. 0113-014R. [Last accessed on 2020 Jan 29].

6. Gibbons M, Hopkins D. How experiential is your experience-based program? J Experiential Educ 1980;3:32-7.

7. Susi T, Johannesson M, Backlund P. Serious Games-An Overview. Skovde, Sweden: Institutionen för kommunikation och Information; 2007. Available from: http://www.diva-portal.org/smash/record. jsf?pid=diva2\%3A2416\&dswid $=5319$. [Last accessed on 2020 Feb 26].

8. Prensky M. Digital game-based learning. Comput Entertain 2003;1:21.

9. Allery LA. Educational games and structured experiences. Med Teach 2004;26:504-5.

10. Bochennek K, Wittekindt B, Zimmermann SY, Klingebiel T. More than mere games: A review of card and board games for medical education More than mere games: A review of card and board games for medical education. Med Teach 2007;29:941-8.

11. Ober CP. Novel card games for learning radiographic image quality and urologic imaging in veterinary medicine. J Vet Med Educ 2016;43:263-70. Available from: https://jvme.utpjournals.press/ doi/10.3138/j vme. 0715-108R. [Last accessed on 2020 Jan 17].

12. Ober CP. Use of a novel board game in a clinical rotation for learning thoracic differential diagnoses in veterinary medical imaging. Vet Radiol Ultrasound 2017;58:127-32.

13. Valente P, Lora PS, Landell MF, Schiefelbein CS, Girardi FM, Souza LD, et al. Game for teaching antimicrobial mechanisms of action. Med Teach 2009;31:e383-92. Available from: http://www.ncbi.nlm.nih. gov/pub med/19811173. [Last accessed on 2019 Jun 17].

14. Karbownik MS, Wiktorowska-Owczarek A, Kowalczyk E, Kwarta P, Mokros L, Pietras T. Board game versus lecture-based seminar in the teaching of pharmacology of antimicrobial drugs-a randomized controlled trial. FEMS Microbiol Lett 2016;363:45. Available from: https://academic.oup.com/femsle/article-abstract/363/7/ fnw045/2197778. [Last accessed on 2019 Jun 17].

15. Wouters $P$, van Nimwegen C, van Oostendorp H, van Der Spek ED. A meta-analysis of the cognitive and motivational effects of serious games. J Educ Psychol 2013;105:249-65.

16. Sitzmann T. A meta-analytic examination of the instructional effectiveness of computer-based simulation games. Pers Psychol 2011;64:489-528. Available from: http://doi.wiley.com $/ 10.1111 / \mathrm{j}$ 174 4-6570.2011.01190.x. [Last accessed on 2020 Jan 22].

17. Brown PC, Roediger HL, McDaniel MA. To learn, retrieve. In: Make it Stick: The Science of Successful Learning. Cambridge, MA: The Belknap Press of Harvard University Press; 2014. p. 23-45. Available from: https://www.jstor.org/stable/j.ctt6wprs3. [Last accessed on 2018 Jul 17].

18. Larsen DP, Butler AC, Roediger HL $3^{\text {rd }}$. Repeated testing improves long-term retention relative to repeated study: A randomised controlled trial. Med Educ 2009;43:1174-81.

19. Larsen DP, Butler AC, Roediger HL $3^{\text {rd }}$. Comparative effects of test-enhanced learning and self-explanation on long-term retention. Med Educ 2013;47:674-82.

20. Larsen DP. Planning Education for Long-Term Retention: The Cognitive Science and Implementation of Retrieval Practice. Semin Neurol 2018;38:449-56

21. Dankbaar M. Serious games and blended learning; effects on performance and motivation in medical education. Perspect Med Educ 2017;6:58-60.

22. Chanel G, Rebetez C, Bétrancourt M, Pun T. Emotion assessment from physiological signals for adaptation of game difficulty. IEEE Trans Syst Man, Cybern Part A Syst Hum 2011;41:1052-63.

23. Harasym PH, Price PG, Brant R, Violato C, Lorscheider FL. Evaluation of negation in stems of multiple-choice items. Eval Health Prof 1992;15:198-220. Available from: http://journals.sagepub.com/do i/10.1177/016327879201500205. [Last accessed on 2020 Feb 06].

24. Tamir P. Positive and negative multiple choice items: How different are they? Stud Educ Eval 1993;19:311-25.

25. Balaha MH. Simplified guidelines for multiple-choice question writing to increase faculty compliance and ensure valid student results. Educ Med J 2019;14:1-17.

26. McCoubrie P. Improving the fairness of multiple-choice questions: A literature review. Med Teach 2004;26:709-12.

27. Laakkonen J, Muukkonen H. Fostering students' collaborative learning competencies and professional conduct in the context of two gross anatomy courses in veterinary medicine. Anat Sci Educ 2019;12:154-63.

28. Thurman J, Volet SE, Bolton JR. Collaborative, case-based learning: How do students actually learn from each other? J Vet Med Educ 2009;36:297-304.

29. Khosa DK, Volet SE. Promoting effective collaborative case-based learning at university: A metacognitive intervention. Stud High Educ 2013;38:870-89. 
Appendix

Appendix A: Detailed gameplay of Snouts and Tails

\section{Gameplay}

Players begin by placing the game board on a flat surface. Each player then picks a pawn and places it at the beginning of the path on the square with a sick pig icon. Each player then rolls the dice, and the player with the highest number plays first. After the first play ends, the player to his/her left plays.

On a player's turn, the player must roll the dice and move his/her pawn forward the number of spaces as rolled on the dice. If the pawn lands on a question mark, the player picks up the first card on the question mark card deck and hands it to the player on his/her right, who reads the question to him/her. If their answer is right, the pawn is moved forward one space. If the answer is wrong, the pawn is moved one step back. The question mark card is then placed in a discarded pile and the turn of the player ends.

If the pawn lands on a warning sign, the player picks up the first card of the warning sign card deck and follows the instructions. If the instructions require the pawn to move and if the pawn after moving lands on a question mark, the player needs to answer a question mark card as described above. The warning card is put in a discarded pile after it has been used. The turn of the player then ends.

If the pawn lands on the veterinary caduceus, the player picks up the first card in the veterinary caduceus card deck. The player needs to answer the question written on the card. If the answer is right, the player moves his/her pawn two spaces forward; if not, the pawn is moved two spaces back. The caduceus card is then put in a discarded pile.

When the card decks run out, the cards are shuffled and placed back, face down, in a pile on the table.

\section{End of the game}

There are two possible endings:

Ending 1: The game ends when one player reaches the end of the path. It is not necessary for the player to land exactly on the final space. For example, if a player's pawn is 2 spaces away from the arrival and the dice reads 3 or more, the player wins.

Ending 2: The player needs to land exactly on the arrival space to win; if the number on the dice is too big, the player's pawn backs up on the path. 